\title{
Relationship between Secretion of Platelet Factor 4 and Thrombin Generation during In Vitro Blood Clotting
}

\author{
Marc A. Shuman, Division of Hematology-Oncology, Department of Medicine, \\ University of California, San Francisco, California 94143 \\ Shirley P. LeVINE,Audie L. Murphy Memorial Veterans Administration Hospital and \\ the Division of Hematology, Department of Medicine, University of Texas Health \\ Science Center, San Antonio, Texas 78284
}

\begin{abstract}
A B S T RACT We have studied the effects of both impaired prothrombin activation and direct inhibition of thrombin on the platelet release reaction in clotting blood to determine the role of thrombin in this process. In blood from two patients with congenital Factor $\mathrm{V}$ deficiency, prothrombin activation during spontaneous in vitro clotting was delayed and decreased. Secretion of platelet Factor 4 was also delayed and was detected only after thrombin formation was initiated. Addition of a small amount of normal plasma to the patients' blood in vitro corrected the abnormalities in both thrombin formation and the platelet release reaction in parallel fashion. A delay in the onset of secretion of platelet Factor 4 was also observed when thrombin generated in normal blood during spontaneous in vitro clotting was inhibited by either purified hirudin or anti-thrombin Fab. These observations suggest that thrombin is the essential stimulus for platelet secretion during in vitro blood clotting.

The effect of inhibitors of the platelet release reaction on prothrombin activation during in vitro blood clotting was also studied. When either prostacyclin or the combination of prostaglandin $\mathrm{E}_{1}$ and $\mathrm{N}^{6} 0^{21}$ dibutyryl cyclic AMP was added, secretion of platelet Factor 4 was inhibited $85-95 \%$. We were unable to detect any inhibition of initiation of prothrombin activation or inhibition of that part of thrombin generation associated with clotting. These results indicate either that the platelet release reaction may not be required for the initiation of prothrombin activation or only a very limited amount of secretion may be necessary for normal generation of thrombin to occur.
\end{abstract}

A preliminary report of this work was presented at the Annual Meeting of the American Federation for Clinical Research, Washington, D. C., May 1979, and was published in abstract form in 1979. Clin. Res. 27: 307A.

Dr. Levine is a Clinical Investigator.

Received for publication 6 August 1979 and in revised form 28 September 1979.

\section{INTRODUCTION}

The interaction between platelets and clotting factors is a complex one. Activation of the coagulation system results in the formation of thrombin, which clots fibrinogen, and in addition stimulates both the platelet release reaction ${ }^{1}$ and platelet aggregation. Platelets, on the other hand, serve as cofactors in two reactions in the coagulation pathway: the activation of Factor $X$ and the activation of prothrombin (1). Evidence of a role for platelets in the early steps of the contact activation pathway has also been presented (2). Using radioimmunoassays for thrombin and a protein secreted by platelets, platelet Factor $4\left(\mathrm{PF}_{4}\right){ }^{2}{ }^{2}$ we have previously shown that a close correlation exists between thrombin formation and the platelet release reaction during spontaneous in vitro clotting of normal blood (3). The onset of thrombin formation and secretion of $\mathrm{PF}_{4}$ precedes visible clotting by several minutes. The concentrations of thrombin and $\mathrm{PF}_{4}$ in plasma then rise gradually in a parallel fashion until shortly before clotting, when, at relatively high thrombin concentrations, the major portion of platelet secretion of $\mathrm{PF}_{4}$ occurs.

We now report the results of experiments that further clarify the relationship between prothrombin activation and the platelet release reaction. In the first series of experiments, we have examined the consequences of delayed prothrombin activation on initiation of the platelet release reaction during the clotting of blood from two women with congenital Factor V deficiency. To determine the effects on the platelet release reaction of direct inhibition of the thrombin formed during spontaneous clotting, we added either

\footnotetext{
${ }^{1}$ The term "release reaction" refers to platelet secretion and the terms are used interchangeably.

${ }^{2}$ Abbreviations used in this paper: dbcAMP, $\mathrm{N}^{6} 0^{2}$-dibutyryl cyclic AMP; $\mathrm{PGE}_{1}$, prostaglandin $\mathrm{E}_{1} ; \mathrm{PGI}_{2}$, prostacyclin; $\mathrm{PF}_{4}$, platelet Factor 4 .
} 
hirudin or an anti-thrombin antibody to freshly drawn normal blood and measured the subsequent platelet secretion of $\mathrm{PF}_{4}$.

In a second series of experiments, to blood from normal volunteers we added agents that elevate platelet cyclic AMP and measured subsequent thrombin and $\mathrm{PF}_{4}$ formation. The purpose of these experiments was to determine how inhibition of platelet secretion affects the initiation and time-course of thrombin generation during spontaneous clotting.

\section{METHODS}

Materials. Sources for most reagents have been reported (3-5). Prostacyclin $\left(\mathrm{PGI}_{2}\right)$ was synthesized by K. C. Nicolau of the University of Pennsylvania, Philadelphia, Pa. (6) and kindly supplied by Dr. J. Bryan Smith of Thomas Jefferson Medical College, Philadelphia, Pa. Rabbit anti-human thrombin $\mathrm{Fab}$ and $\mathrm{Fab}$ from normal rabbit immunoglobulin $(\mathrm{Ig}) \mathrm{G}$ were prepared as described (7). Prostaglandin $\mathrm{E}_{1}$ $\left(\mathrm{PGE}_{1}\right)$ was generously provided by Ono Pharmaceutical Co., Ltd., Japan.

Very high purity hirudin $(10,000-12,000 \mathrm{U} / \mathrm{mg})$ was generously provided by Dr. J. Fenton, II, Albany, N. Y. The original material had been purified by Dr. F. Markwardt, East Germany, and recycled by Dr. Fenton after crystallographic studies of hirudin and its complex with thrombin. ${ }^{3}$ One hirudin unit is defined as that which inhibits one NIH unit of thrombin.

Thrombin generation and secretion of $P F_{4}$. With the two syringe technique, blood was obtained from the two patients and from normal volunteers and was immediately placed into new polypropylene tubes. One of the tubes contained no other additions and the blood was allowed to clot spontaneously. A second tube contained $3.8 \%$ sodium citrate $(\mathrm{l}: 9, \mathrm{vol} / \mathrm{vol})$ and was used as an anticoagulated control (3). Additional tubes contained substances that were added to the blood to determine their effect on prothrombin activation and platelet secretion (see below). Samples were removed from each tube immediately after collection of the blood and at regular intervals, and were assayed for either $\mathrm{PF}_{4}$ or thrombin $(3-5)$.

$\mathrm{PF}_{4}$ values of samples from the tube containing anticoagulated blood were subtracted from $\mathrm{PF}_{4}$ values of blood measured at comparable times after collection in the tubes not containing anticoagulant (3). The net basal values ranged between $0-50 \mathrm{ng} / \mathrm{ml}$ depending upon the interval elapsed from venipuncture to processing of the first sample.

Studies in patients with congenital Factor $V$ deficiency. Two patients with severe congenital Factor $V$ deficiency were studied: patient K.H. on one occasion and patient E.N. on two occasions. Blood was drawn and distributed into three tubes as described above. To the third tube, fresh normal plasma was added as a source of Factor V.

Effects of hirudin. Blood was obtained from normal donors and distributed into three tubes as described above. Hirudin was immediately added to the third tube in a final concentration of $5 \mathrm{U} / \mathrm{ml}$. This experiment was performed on blood from two volunteers.

Effects of anti-thrombin Fab. Blood obtained from normal donors was distributed into four tubes as described above. Anti-thrombin Fab was added to the third tube and control

\footnotetext{
${ }^{3}$ Landis, B. H., J. W. Fenton, II, and F. Markwardt. Manuscript in preparation.
}

rabbit $F$ ab to a fourth, each at a final concentration of $0.16 \mathrm{mg} / \mathrm{ml}$. Two donors were used for this experiment.

Effect of antiplatelet agents. (a) Blood was collected from normal volunteers and distributed into three tubes. To the third, $\mathrm{PGI}_{2}$ was added in a final concentration of $50 \mathrm{n} \mathrm{M}$. Four donors were used for this experiment.

(b) $\mathrm{PGE}_{1}$ and $\mathrm{N}^{6} 0^{2}$-dibutyryl cyclic AMP (dbcAMP) were added to freshly drawn blood in a final concentration of $10 \mu \mathrm{g} / \mathrm{ml}$ and $1 \mathrm{mM}$, respectively. The $\mathrm{PGE}_{1}$ stock preparation was dissolved in ethanol at a concentration of $10 \mathrm{mg} / \mathrm{ml}$. The dbcAMP preparation $(100 \mathrm{mM})$ was dissolved in $0.14 \mathrm{M}$ $\mathrm{NaCl}-0.01 \mathrm{M}$ sodium phosphate, $\mathrm{pH}$ 7.4. Two donors were used in this experiment.

(c) Three normal volunteers ingested $600 \mathrm{mg}$ of aspirin at 12-h intervals beginning $24 \mathrm{~h}$ before blood collection (total dose, $1,800 \mathrm{mg}$ ). Serum salicylate levels were measured to assess compliance (8). Blood was collected from each volunteer and thrombin formation and secretion of $\mathrm{PF}_{4}$ determined as described above.

\section{RESULTS}

Prothrombin activation and the platelet release reaction in Factor $V$-deficient patients. To determine the effect of delayed prothrombin activation on platelet secretion of $\mathrm{PF}_{4}$, blood was obtained from two patients with congenital Factor $\mathrm{V}$ deficiency (plasma Factor V, 0\%) (9). Immediately after blood collection, serial samples were removed for assay of $\mathrm{PF}_{4}$ and thrombin in plasma and serum. The onset of thrombin formation was markedly delayed in the blood from patient E.N., a woman with a severe bleeding history (Fig. 1A). No thrombin was detectable for over $100 \mathrm{~min}$ after blood collection (normal, 4-8 min), and once initiated, thrombin generation progressed slowly. The interval from initiation of thrombin formation to clotting, which occurred at $203 \mathrm{~min}$, was prolonged (patient, $46 \mathrm{~min}$; normal, 12-24 min). The concentration of thrombin in serum was reduced (patient, $80 \mathrm{ng} / \mathrm{ml}$; normal, $500-1,500 \mathrm{ng} / \mathrm{ml}$ ).

An abnormality was also seen in the platelet release reaction. The plasma $\mathrm{PF}_{4}$ concentrations in the clotting samples were no higher than in the anticoagulated control samples for the first $200 \mathrm{~min}$. Because only a limited amount of blood remained in the tube, we were unable to measure $\mathrm{PF}_{4}$ levels during the time of maximal thrombin formation (206-240 min); however, the $\mathrm{PF}_{4}$ concentration in an overnight serum specimen was normal $(5,900 \mathrm{ng} / \mathrm{ml})$.

When the patient's blood was mixed with $1 / 18(\mathrm{vol} / \mathrm{vol})$ fresh normal plasma (Fig 1A, P + C), the abnormalities described above were almost completely corrected (clotting occurred at $27 \mathrm{~min}$ ). The serum thrombin concentration was only slightly decreased $(400 \mathrm{ng} / \mathrm{ml})$, and a comparable improvement in the platelet release reaction was observed. Secretion of $\mathrm{PF}_{4}$ was initiated by $18 \mathrm{~min}$ and increased rapidly over the next $18 \mathrm{~min}$, paralleling thrombin formation. This latter observation indicates that the marked delay in the platelet secretion of the blood of patient E.N. described above was not 

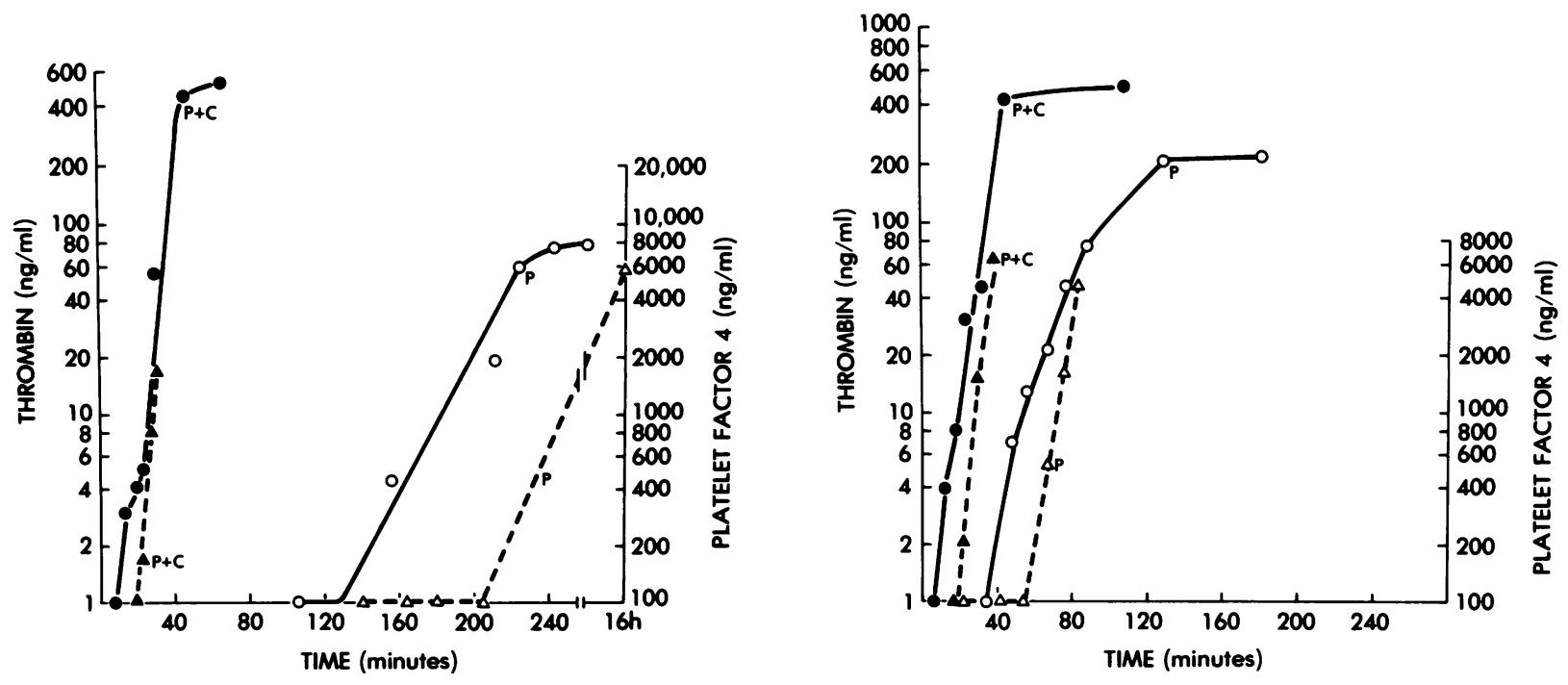

FIGURE 1 Thrombin generation and secretion of $\mathrm{PF}_{4}$ in blood from patients with congenital Factor V deficiency. Blood was drawn from patients (patient E.N., Fig. 1A; patient K.H., Fig. 1B), immediately placed into polypropylene tubes, and allowed to clot spontaneously. To one tube, fresh normal plasma was added immediately after collection of the blood. Samples were removed serially and assayed for thrombin $(\mathrm{O}, \mathrm{O})$ or $\mathrm{PF}_{4}(\Delta, \boldsymbol{\Delta}) . \mathrm{P}+\mathrm{C}$, mixture of patient's blood and normal plasma (closed symbols); P, Patient's blood (open symbols).

because of an abnormality in the release reaction, but rather to an inadequate thrombin stimulus.

The second patient (patient K.H.) had a much milder clinical history of bleeding problems. Thrombin formation was abnormal in the patient's blood (Fig. 1B) but these abnormalities were less than those observed in the first patient. Thrombin was first detected at $48 \mathrm{~min}$, and the interval until clotting was only slightly prolonged, $28 \mathrm{~min}$ (clotting time, $76 \mathrm{~min}$ ). The final thrombin concentration $(200 \mathrm{ng} / \mathrm{ml})$, although reduced, was 2.5-fold higher than that of the first patient's serum. The onset of $\mathrm{PF}_{4}$ secretion was also delayed $(50 \mathrm{~min})$, but in contrast to the first patient, virtually complete platelet secretion had occurred by the time of clotting. The delay in the release reaction was similar to the delay in prothrombin activation, and $\mathrm{PF}_{4}$ secretion occurred only after thrombin formation was initiated. When this patient's blood was mixed $1 / 10$ ( $\mathrm{vol} / \mathrm{vol}$ ) with normal plasma (Fig. 1B), the abnormalities in thrombin formation and platelet secretion were corrected in a parallel manner (clotting time, $31 \mathrm{~min}$ ).

These studies suggest that thrombin formation must occur before platelet secretion can take place, and that a threshold concentration of thrombin must be reached before release of $\mathrm{PF}_{4}$ is initiated. Furthermore, the addition of normal plasma to correct Factor V-deficient blood results in a simultaneous correction of thrombin generation and platelet secretion.

Effect of inhibition of thrombin activity on platelet release of $\mathrm{PF}_{4}$. To examine further the role of thrombin in platelet secretion during spontaneous in vitro blood clotting, specific inhibitors of thrombin were added to normal blood immediately after its collection, and the release of $\mathrm{PF}_{4}$ was determined in serial samples. Addition of the leech anti-thrombin, hirudin, to blood resulted in an inhibition of clotting (hirudin, $38 \mathrm{~min}$; control, $24 \mathrm{~min}$ ) and platelet secretion. Both the time of onset of platelet secretion of $\mathrm{PF}_{4}$ and completion were delayed (Fig. 2). We were unable to measure thrombin

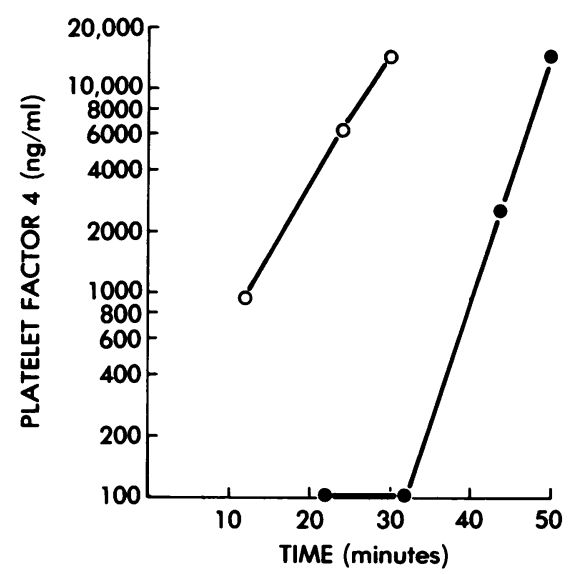

FIGURE 2 Effect of purified hirudin on secretion of $\mathrm{PF}_{4}$ during clotting of normal blood. After venipuncture, blood was distributed into polypropylene tubes and allowed to clot spontaneously. To one tube, purified hirudin was added immediately after collection of the blood. Plasma and serum $\mathrm{PF}_{4}$ concentrations were determined on serial samples from the control and hirudin-treated blood. (O) Hirudin $(5 \mathrm{u} / \mathrm{ml})$; (O) control. 
accurately by radioimmunoassay in the samples to which hirudin was added for reasons that are unclear; however, it may be that the ${ }^{125}$ I-thrombin used in the radioimmunoassay preferentially bound to hirudin rather than to the antibody.

When monospecific Fab fragments of a rabbit antibody against thrombin were added to blood, a prolongation of the time until clotting was observed (anti-thrombin Fab, $43 \mathrm{~min}$; control, $21 \mathrm{~min}$ ). A delay in the onset of $\mathrm{PF}_{4}$ secretion and a two-fold prolongation of the time at which half-maximal release of $\mathrm{PF}_{4}$ occurred were noted (Fig. 3). Addition of nonimmune rabbit Fab had no effect on platelet release of $\mathrm{PF}_{4}$. The similar inhibitory effect on platelet release of $\mathrm{PF}_{4}$ by two different but specific thrombin antagonists was additional evidence that thrombin is the primary stimulus for platelet secretion during blood clotting.

Effect of antiplatelet agents on thrombin formation and the platelet release reaction associated with in vitro blood clotting. To determine whether inhibition of the platelet release reaction affects prothrombin activation, either $\mathrm{PGI}_{2}$ or $\mathrm{PGE}_{1}$ and dbcAMP were

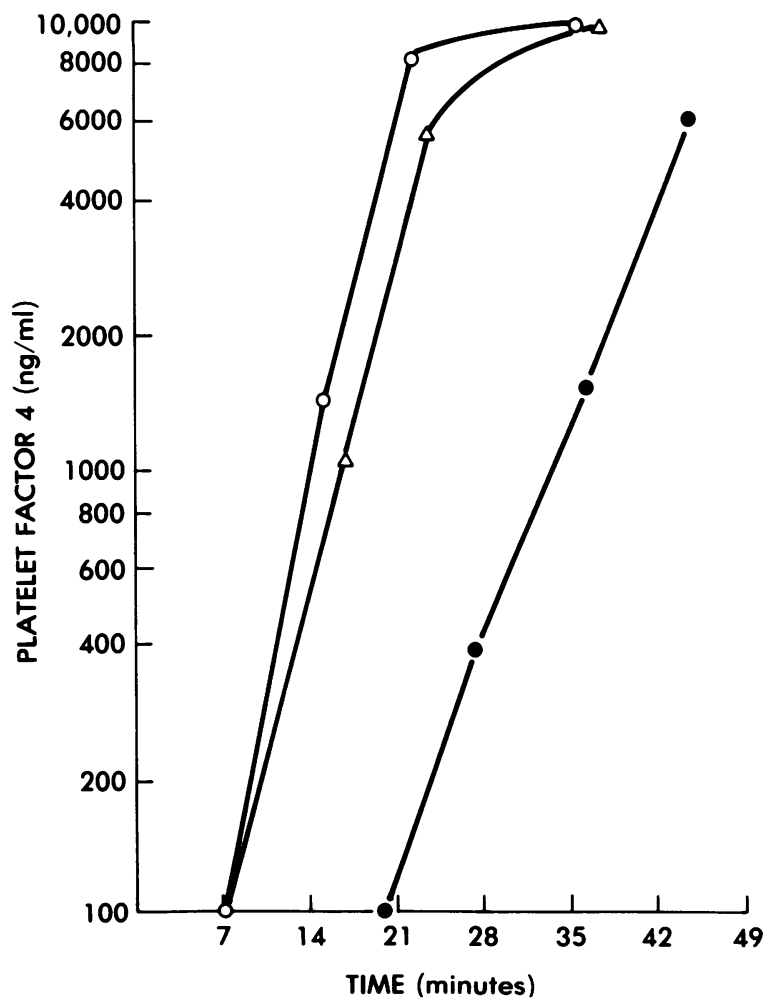

FIgURE 3 Effect of anti-thrombin Fab on secretion of $\mathrm{PF}_{4}$ during clotting of normal blood. Blood was collected, immediately placed into polypropylene tubes, and allowed to clot. To one tube, anti-thrombin Fab was added after blood collection; to another, nonimmune Fab. Plasma and serum $\mathrm{PF}_{4}$ concentrations were determined on serial samples from each tube. (O) Control; (O) rabbit anti-human thrombin Fab; $(\triangle)$ nonimmune Fab. added to freshly drawn blood immediately after collection. When $\mathrm{PGI}_{2}$ was added to whole blood, the clotting time in four experiments was within the upper limits of normal (clotting time, 27-29 min; normal range, 20-30 $\mathrm{min}$ ). There was neither a delay in the initial appearance of thrombin nor a decrease in subsequent thrombin formation compared to the control samples (Fig. 4). Inhibition (85-95\%) of $\mathrm{PF}_{4}$ secretion was observed at $20 \mathrm{~min}$, as shown in Fig. 4 . Although the thrombin concentration had risen to $30 \mathrm{ng} / \mathrm{ml}$, only $1.3 \%$ of $\mathrm{PF}_{4}$ release had occurred. Note that $90 \%$ of prothrombin activation occurs after clotting of fibrinogen (4). Because we were unable to block platelet secretion of $\mathrm{PF}_{4}$ at the high thrombin concentration present in postclotting serum, we did not obtain information on the importance of the release reaction at this stage of clotting.

Similarly, formation of thrombin was not inhibited when $\mathrm{PGE}_{1}$ and dbcAMP were used to block platelet release of $\mathrm{PF}_{4}$. In fact, a slight shortening of the clotting time (17-20 min) occurred with the addition of these agents. Initiation of thrombin formation was prompt and thrombin generation was rapid (Fig. 5). $\mathrm{PF}_{4}$ secretion was inhibited $>95 \%$ at the time of clotting. A slight shortening of the clotting time of whole blood was also seen with each of these platelet inhibiting agents when used separately (data not shown). The explanation for this is unclear, but presumably cellular changes were responsible for decreased clotting time, since these agents had no effect on the clotting of contact-activated cell-free plasma in which phospholipid was substituted for platelets.

The results of these experiments indicate either that the platelet release reaction may not be required for the initiation of prothrombin activation or only a very

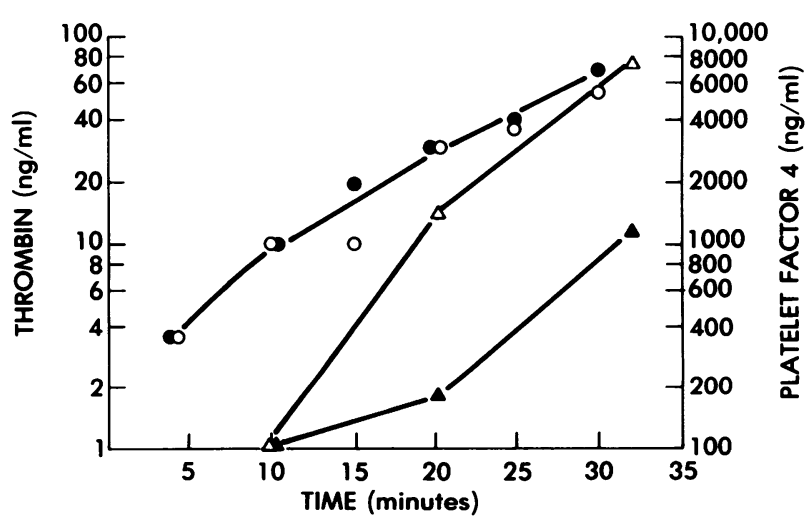

FIGURE 4 Effect of $\mathrm{PGI}_{2}$ on thrombin formation and secretion of $\mathrm{PF}_{4}$ during clotting of normal blood. Blood was drawn and immediately distributed into polypropylene tubes. To one tube, $\mathrm{PGI}_{2}$ was added in a final concentration of $50 \mathrm{nM}$. Samples were removed from each tube and the plasma or serum assayed for thrombin $(\mathrm{O}, \boldsymbol{O})$ of $\mathrm{PF}_{4}(\Delta, \mathbf{\Delta})$. Clotting occurred at $29 \mathrm{~min}$ in the sample to which $\mathrm{PGI}_{2}$ was added $(\odot, \Delta)$ and at $30 \mathrm{~min}$ in the control tube $(O, \Delta)$. 


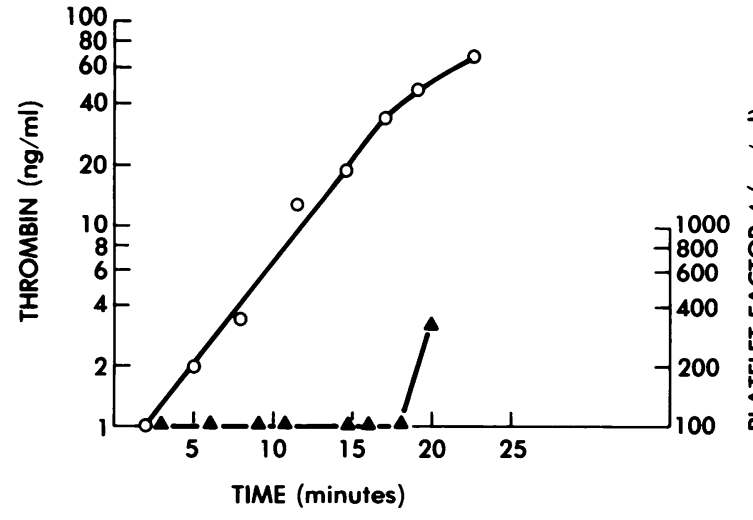

Figure 5 Effect of $\mathrm{PGE}_{1}$ and dbcAMP on thrombin formation and secretion of $\mathrm{PF}_{4}$ during clotting of normal blood. $\mathrm{PGE}_{1}$ (final concentration, $10 \mu \mathrm{g} / \mathrm{ml}$ ) and dbcAMP (final concentration $1 \mathrm{mM}$ ) were added to blood immediately after collection. Serial samples were removed and assayed for thrombin $(\mathrm{O})$ or $\mathrm{PF}_{4}(\boldsymbol{\Delta})$. Clotting occurred at $20 \mathrm{~min}$.

limited amount of secretion may be necessary for normal generation of thrombin to occur.

Effect of aspirin on the platelet release reaction associated with in vitro blood clotting. A variable effect of prostaglandin synthetase inhibitors on thrombin-induced platelet secretion has been reported $(10-12)$. The extent to which platelet secretion is inhibited is related to both the thrombin concentration and the experimental conditions (e.g., stirring of the platelets increases the degree of inhibition) (12). We examined the effect of aspirin on platelet secretion during whole blood clotting, a model that more closely approximates in vivo conditions. Normal donors ingested aspirin in an amount sufficient to completely inhibit prostaglandin formation (13). Blood was drawn and assayed for thrombin and $\mathrm{PF}_{4}$ as described for the previous experiments. Initiation of the release reaction was normal, occurring a few minutes after initiation of thrombin formation (Fig. 6). Secretion of $\mathrm{PF}_{4}$ proceeded normally and was essentially complete at the time of clotting. The serum $\mathrm{PF}_{4}$ concentration, $16.7 \mu \mathrm{g} / \mathrm{ml}$, was within the normal range. Thrombin formation was normal in all three subjects. Because there was no delay in the initiation of the release of $\mathrm{PF}_{4}$ and no dissociation between thrombin formation and platelet secretion of $\mathrm{PF}_{4}$, it appears that even at low thrombin concentrations aspirin does not inhibit the release of alpha granule contents during in vitro blood clotting.

\section{DISCUSSION}

Of those coagulation factors that have been studied, thrombin alone is capable of directly inducing the platelet release reaction. Although it is known to stimulate the release reaction in washed platelets at physiological concentrations (4), no prior studies have dem-

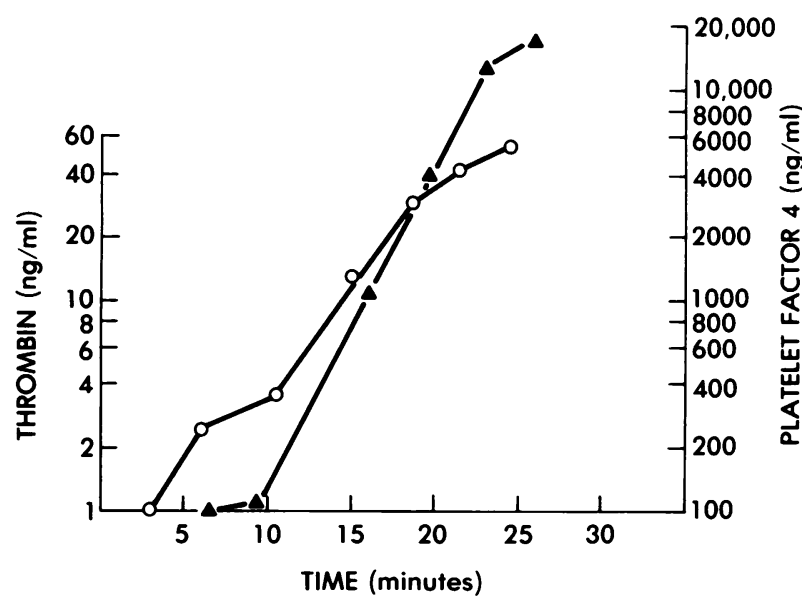

FIGURE 6 Effect of aspirin on thrombin formation and secretion of $\mathrm{PF}_{4}$ during blood clotting. Blood was drawn from a normal donor who had ingested $1,800 \mathrm{mg}$ of aspirin during the preceding $24 \mathrm{~h}$; it was immediately placed into polypropylene tubes. Serial samples were removed and assayed for thrombin (O) or $\mathrm{PF}_{4}(\mathbf{\Delta})$.

onstrated that thrombin is the primary stimulus for platelet secretion during blood clotting. We have previously shown that platelet secretion of the alpha granule protein, $\mathrm{PF}_{4}$, closely parallels thrombin formation during in vitro clotting of normal blood (3). We have extended these observations in studies of the platelet release reaction in which blood from two patients with Factor V deficiency was used. In addition to delayed and decreased thrombin formation, a delay in the platelet release reaction was observed in the blood of each patient. In both instances, no secretion of $\mathrm{PF}_{4}$ occurred above that seen in the anticoagulated control samples before thrombin was formed. Inasmuch as Factor $\mathrm{V}$ is required only for the last step in coagulation, prothrombin activation, the delay in the platelet release reaction must be caused by impaired thrombin formation rather than by another coagulation factor whose activation precedes that of prothrombin. That $\mathrm{PF}_{4}$ secretion becomes normal when the abnormalities in prothrombin activation are corrected is evidence for a direct relationship between thrombin formation and platelet secretion.

Not only were there differences in the results of the patients' studies compared to normal subjects, but in addition, the results from the two patients differed markedly from each other. Patient E.N. had a considerably longer delay in both prothrombin activation and platelet secretion than patient K.H., although each had 0\% plasma Factor $\mathrm{V}$ and similar abnormalities in their conventional coagulation laboratory tests. Patient E.N. also had a more striking clinical history than Patient K.H.; she had required transfusion therapy for bleeding on over 50 occasions, whereas patient K.H. has been transfused on only four occasions, all of which were 
necessitated by obstetrically related hemorrhage (9). The explanation for the differences in thrombin formation between the two patients is unknown, as is the relationship of these observations to the differences in the clinical severity of their disease. Miletich et al. (9) studied the binding of [ $\left.{ }^{125} I\right]$ Factor $X_{a}$ to washed platelets from patients with Factor $\mathrm{V}$ deficiency, including the two patients we have studied, and observed decreased binding in each case. A more marked abnormality was observed with Patient E.N.'s platelets, however. She had $0 \%$ of normal binding of [ $\left.{ }^{125} \mathrm{I}\right] \mathrm{Factor}$ $\mathrm{X}_{\mathrm{a}}$ to her platelets, whereas Patient K.H. had $15 \%$ of normal binding. These authors suggested that the differences in Factor $X_{a}$ binding were a result of differences in the severity of their platelet Factor $\mathrm{V}$ deficiency. Patient E.N. had no platelet Factor V activity. The differences we observed in the whole blood of these two patients in contrast to the absence of marked differences in their plasma coagulation abnormalities is consistent with this hypothesis. It will be necessary for us to study additional patients with Factor $\mathrm{V}$ deficiency before the relevance of these laboratory abnormalities to the pathophysiology of this disease can be determined.

Additional evidence for the essential role of thrombin in the platelet release reaction induced by blood clotting was obtained when thrombin activity was inhibited directly by either hirudin or anti-thrombin Fab. In each experiment, a notable delay occurred in the clotting of fibrinogen and the release of $\mathrm{PF}_{4}$ from platelets. Although we were unable to measure the endogenous thrombin concentrations in these experiments, the specificity of these inhibitors for thrombin indicates that inhibition of thrombin was responsible for the abnormal platelet release of $\mathrm{PF}_{4}$.

The platelet secretion that eventually occurred probably did so because the concentrations of hirudin or anti-thrombin $\mathrm{Fab}$ were insufficient to inhibit the high concentrations of thrombin formed at this stage of prothrombin activation (4). Also, failure to obtain more marked inhibition with the anti-thrombin Fab may be explained by a greater affinity of thrombin for platelets than the antibody.

Although considerable evidence exists to suggest a physiologically important role for platelets in the activation of the coagulation system $(1,2,16)$, the precise mechanism by which this occurs is unknown. Previous studies indicate that platelets must be activated before their procoagulant activity becomes available (17). The nature of the physical or chemical changes, or both, that constitute "activation" is poorly understood, however. Factor $\mathrm{X}_{\mathrm{a}}$ binds to washed platelets only after they have undergone the release reaction (16). Once platelet Factor $\mathrm{V}$ has been secreted it serves to bind Factor $\mathrm{X}_{\mathrm{a}}$ to the platelet. The relevance of these observations to physiological coagulation is unclear, since Factor $\mathrm{V}$ is normally present in plasma. Moreover, evidence has been provided that activation of platelets with ADP or collagen does not shorten the clotting time of platelet-rich plasma compared to plasma containing a phospholipid substitute for platelets (18).

There are several possible explanations for our observation that prothrombin activation occurs normally in spite of marked inhibition of the platelet release reaction. It may be that rather than the release reaction, a conformational change in the platelet membrane is sufficient for activation. We have no information as yet on the effect of platelet inhibitors on changes in either the platelet membrane or shape in our experiments. Alternatively, the platelet release reaction may be required for procoagulant activity, but a small amount of release may be sufficient to provide this activity. Another possibility is that procoagulant substances are released by a mechanism different from that which releases alpha granules, and that release of procoagulant substances was not blocked in our experiments. The release of Factors V and VIII from platelets appears to be similar to that of alpha granule contents $(16,19,20)$. However, the significance of this observation relative to platelet procoagulant activity is unknown.

The differences in whole blood clotting between the two patients with Factor $V$ deficiency suggest that the small amount of Factor $\mathrm{V}$ activity contained in Patient K.H.'s platelets (9) may have partially corrected the abnormalities in thrombin generation associated with her plasma Factor $\mathrm{V}$ deficiency. The importance of this observation in relation to normal blood clotting, when normal amounts of plasma Factor $\mathrm{V}$ are present, is unknown, however. Moreover, the question remains as to what initiates platelet activation, if this is required before platelets are able to provide their procoagulant activity. Determination of the role of platelets in the coagulation scheme awaits characterization of the nature of platelet procoagulant activity and a demonstration of how this activity becomes available under physiological circumstances.

\section{ACKNOWLEDGMENTS}

The authors wish to thank Ms. Linda Krentz for her expert technical assistance. Also, we would like to thank Doctors Sandra Schiffman, Donald Feinstein, Philip Majerus, and Douglas Triplett for assisting us in the study of the patients with Factor V deficiency and for the use of their laboratory facilities.

This work was supported by grant HL 21403 (Dr. Shuman) and the Medical Research Service, Veterans Administration (Dr. Levine).

\section{REFERENCES}

1. Walsh, P. N., and R. Biggs. 1972. The role of platelets in intrinsic factor- $\mathrm{X}_{\mathrm{a}}$ formation. $\mathrm{Br}$. J. Haematol. 22: 743-760. 
2. Walsh, P. N., and J. H. Griffin. 1978. The role of human platelets in the contact phase of blood coagulation. Clin. Res. 26: 509A. (Abstr.)

3. Shuman, M. A., and S. P. Levine. 1978. Thrombin generation and secretion of platelet Factor 4 during blood clotting. J. Clin. Invest. 61: 1102-1106.

4. Shuman, M. A., and P. W. Majerus. 1976. The measurement of thrombin in clotting blood by radioimmunoassay. J. Clin. Invest. 58: 1249-1258.

5. Levine, S. P., and L. S. Krentz. 1977. Development of a radioimmunoassay for human platelet Factor 4 . Thromb Res. 11: 673-686.

6. Nicolaou, K. C., W. E. Barnette, G. P. Gasic, R. L. Magolda, W. J. Sipio, M. J. Silver, J. B. Smith, and C. M. Ingerman. 1977. Rapid and easy preparation of prostacyclin. Lancet. I: $1058-1059$.

7. Shuman, M. A., D. M. Tollefsen, and P. W. Majerus. 1976. The binding of human and bovine thrombin to platelets. Blood. 47: 43-54.

8. Trinder, P. 1954. Rapid determination of salicylate in biological fluids. Biochem. J. 57: 301-303.

9. Miletich, J. P., D. W. Majerus, and P. W. Majerus. 1978. Patients with congenital Factor $V$ deficiency have decreased Factor $\mathrm{X}_{\mathrm{a}}$ binding sites on their platelets. J. Clin. Invest. 62: 824-831.

10. Packham, M. A., M. A. Guccione, J. P. Greenberg, R. L. Kinlough-Rathbone, and J. F. Mustard. 1977. Release of ${ }^{14} \mathrm{C}$-serotonin during initial platelet changes induced by thrombin, collagen or A23187. Blood. 50: 915-926.

11. Kaplan, K. L., M. J. Broekman, A. Chernoff, G. R. Lesznik, and M. Drillings. 1979. Platelet alpha-granule proteins: studies on release and subcellular localization. Blood. 53: 604-618.

12. Charo, I. F., R. D. Feinman, and T. C. Detwiler. 1977. Interrelations of platelet aggregation and secretion. $J$. Clin. Invest. 60: 866-873.

13. Burch, J. W., N. Stanford, and P. W. Majerus. 1978. Inhibition of platelet prostaglandin synthetase by oral aspirin. J. Clin. Invest. 61: 314-319.

14. Mustard, J. F., D. W. Perry, R. L. Kinlough-Rathbone, and M. A. Packham. 1975. Factors responsible for ADPinduced release reaction of human platelets. Am. J. Physiol. 228: 1757-1765.

15. Weiss, H. J., L. M. Aledort, and S. Kochwa. 1968. The effect of salicylates on the hemostatic properties of platelets in man. J. Clin. Invest. 47: 2169-2180.

16. Miletich, J. P., C. M. Jackson, and P. W. Majerus. 1978. Properties of the Factor $\mathrm{X}_{\mathrm{a}}$ binding site on human platelets. J. Biol. Chem. 253: 6908-6916.

17. Fantl, P., and H. A. Ward. 1958. The thromboplastic component of intact blood platelets is present in masked form. Aust. J. Exp. Biol. Med. Sci. 36: 499-504.

18. Vecchione, J., and M. B. Zucker. 1975. Procoagulant activity of platelets in recalcified plasma. Br. J. Haematol. 31: 423-428.

19. Koutts, J., P. N. Walsh, E. F. Plow, J. W. Fenton, II, B. N. Bouma, and T. S. Zimmerman. 1978. Active release of human platelet Factor VIII-related antigen by adenosine diphosphate, collagen, and thrombin. J. Clin. Invest. 62: 1255-1263.

20. Osterud, B., S. I. Rapaport, and K. K. Lavine. 1977. Factor $\mathrm{V}$ activity of platelets: Evidence for an activated Factor V molecule and for a platelet activator. Blood. 49: 819-834. 